\title{
SORÇÃO DE DIURON EM MINERAIS DA FRAÇÃO ARGILA
}

\author{
Izabel Cristina Leinig Araujo e Vander de Freitas Melo* \\ Departamento de Solos e Engenharia Agrícola, Setor de Ciências Agrárias, Universidade Federal do Paraná, Rua dos Funcionários, \\ 1540, 80035-050 Curitiba - PR, Brasil \\ Gilberto Abate e Rafael Garrett Dolatto \\ Departamento de Química, Universidade Federal do Paraná, Centro Politécnico, CP 26077, 81531-990 Curitiba - PR, Brasil
}

Recebido em 4/7/11; aceito em 27/2/11; publicado na web em 15/6/12

\begin{abstract}
DIURON SORPTION ONTO CLAY MINERAL FRACTIONS. The objective of the present study was to evaluate the adsorption of the herbicide Diuron onto smectite and Fe oxides minerals. Ninety mg of each mineral, $1 \mathrm{~mL}$ of $0.15 \mathrm{~mol} \mathrm{~L}^{-1} \mathrm{CaCl}_{2}$ and $8 \mathrm{~mL}$ of Diuron (0.25-10.00 $\left.\mathrm{mg} \mathrm{L}^{-1}\right)$ were used in triplicates. These materials were shaken, ultra centrifuged and the supernatant collected and analysed on a UV-Vis spectrophotometer. The Diuron presented low adsorption onto clay mineral fractions. Adsorption was greater onto Fe oxides at $\mathrm{pH} 7.0$, possibly due to proximity to the point of zero charge of these minerals.
\end{abstract}

Keywords: smectite; Fe oxides; herbicides.

\section{INTRODUÇÃO}

Ao longo dos anos, o elevado crescimento das atividades agrícolas sempre foi acompanhado pelo intenso uso de pesticidas ${ }^{1-3}$ principalmente no Brasil, que é considerado o maior consumidor do mundo. ${ }^{4}$ Dentre os pesticidas, a classe dos herbicidas - que matam ou suprimem o crescimento de plantas invasoras específicas - é responsável pela maior parte das vendas e do consumo em nível mundial.,

Embora sejam insumos agrícolas de reconhecida importância, a utilização inadequada e sem conhecimento da ação e dos efeitos secundários pode acarretar danos ambientais, o que reforça a necessidade de estudos sobre o seu destino final: o solo. O comportamento de herbicidas no solo é bastante complexo e resulta de vários fatores, dentre os quais, destaca-se o processo de sorção, que denota a interação entre o soluto e a fase sólida do solo. ${ }^{7}$ Esta depende das características químicas da molécula do herbicida ${ }^{1,8,9}$ e das propriedades e dos constituintes do solo. ${ }^{1,9}$

O herbicida Diuron [3-(3,4 diclorofenil)-1,1-dimetilureia] (Figura 1), do grupo químico das fenilureias ${ }^{10-12}$ é parcialmente polar, não ionizável e tem solubilidade em água de $42 \mathrm{mg} \mathrm{L}^{-1} \cdot{ }^{11,13}$ No Brasil é um dos mais utilizados no controle de plantas invasoras da cana-de-açúcar. ${ }^{8,10}$ Além disso, pode ser usado de forma isolada ou combinada com outros herbicidas em culturas de citros, algodão, café, abacaxi, cacau, banana, entre outras. ${ }^{11}$ De acordo com o grau de toxicidade e periculosidade ambiental, é considerado moderadamente tóxico e muito perigoso para o meio ambiente ${ }^{11,14} \mathrm{O}$ coeficiente de partição ou sorção $\left(K_{d}\right)$ do Diuron, que representa a relação entre a concentração do herbicida sorvido ao solo e a concentração do herbicida encontrada na solução de equilíbrio, é de $400 \mathrm{~L} \mathrm{~kg}^{-1} \cdot{ }^{15} \mathrm{~A}$ persistência deste pesticida no ambiente pode ser de 3 meses $^{11}$ a 1 ano. ${ }^{16}$<smiles>CN(C)C(=O)Nc1ccc(Cl)c(Cl)c1</smiles>

Figura 1. Fórmula química estrutural do herbicida Diuron [3-(3,4 diclorofenil)-1,1 dimetilureia]
Na literatura há uma ampla diversidade de trabalhos que abordam a sorção de Diuron em solos e minerais da fração argila. ${ }^{8,10,12,17-19}$ Entretanto, poucos trabalhos sobre Diuron dão enfoque aos minerais encontrados naturalmente nos solos, principalmente usando resíduos concentrados após o tratamento da fração argila com extrações sequenciais. A maior parte dos estudos relaciona a sorção à matéria orgânica. Nos estudos de sorção com o solo (terra fina), há controvérsias sobre os mecanismos de sorção, por se tratar de uma matriz composta, com constituintes coloidais com cargas positivas e negativas e superfícies apolares..$^{20,21}$ Dentre os minerais da fração argila, as esmectitas e os óxidos de Fe apresentam mecanismos distintos quanto à natureza de formação das cargas (permanentes ou estruturais e dependentes de $\mathrm{pH}$ ou variáveis, respectivamente) e de predomínio do sinal das cargas (negativas e positivas na faixa normal de $\mathrm{pH}$ dos solos de 4 a 7).

O grupo das esmectitas, que tem como principal representante nos solos a montmorilonita, é formado por argilominerais 2:1 expansíveis, que apresentam alta área superficial específica (ASE), podendo atingir valores de até $700 \mathrm{~m}^{2} \mathrm{~g}^{-1}$, devido principalmente à área interna, e alta capacidade de troca catiônica (CTC) com valores próximos a $100 \mathrm{cmol}_{\mathrm{c}} \mathrm{kg}^{-1}$. A formação dessa alta carga negativa é resultante, principalmente, da substituição isomórfica de $\mathrm{Al}^{3+}$ por $\mathrm{Mg}^{2+}$ na lâmina octaédrica. ${ }^{20,21}$

Já os óxidos de Fe são formados por uma estrutura básica octaédrica, constituída de Fe e O. Estes octaedros são polimerizados em arranjos compactos, unidos por vértices, faces ou arestas..$^{22,23}$ Esses minerais apresentam menor ASE (90 a $\left.200 \mathrm{~m}^{2} \mathrm{~g}^{-1}\right)$ e baixa CTC (menor que $10 \mathrm{cmol}_{\mathrm{c}} \mathrm{kg}^{-1}$ ). A carga é dependente do $\mathrm{pH}$ do meio, com predomínio de cargas positivas de superfície (CTA capacidade de troca aniônica) para a faixa normal de $\mathrm{pH}$ dos solos (entre 4 e 7). $\mathrm{O}$ valor de $\mathrm{pH}$ onde se tem a igualdade de cargas nos óxidos de ferro $(\mathrm{CTC}=\mathrm{CTA})$ é denominado ponto de carga zero e oscila em torno de $8,0 .^{23}$

O presente trabalho teve como objetivo estudar a sorção do herbicida Diuron em dois minerais concentrados da fração argila de solos (esmectita e óxidos de $\mathrm{Fe}$ ) por representarem ambientes de formação distintos em termos de área superficial específica e predomínio de cargas negativas (CTC) e positivas (CTA). 


\section{PARTE EXPERIMENTAL}

\section{Preparação dos minerais}

Os óxidos de $\mathrm{Fe}$ foram obtidos da fração argila de uma amostra de Latossolo Vermelho Distroférrico húmico (LVDf horizonte $\mathrm{BW} 1$ ), que tem como material de origem o basalto e foi coletado em Cascavel, PR por Ghidin et al.. ${ }^{24}$ Estes autores descreveram a textura do solo como muito argilosa e encontraram teores de óxidos de Fe de $280 \mathrm{~g} \mathrm{~kg}^{-1}$ na fração argila (extração com ditionito-citrato-bicarbonato).

Já a esmectita teve como fonte uma amostra moída de Argilito da Bacia Sedimentar de Curitiba, coletada em Pinhais, PR. Esta bacia tem formação geológica proveniente do Período Quaternário, a qual é conhecida como Formação Guabirotuba e é composta de depósitos pouco consolidados de argilitos, arenitos e arcóseos. ${ }^{25}$

As amostras de LVDf e de Argilito foram secas ao ar, moídas e tamisadas em peneira de $2 \mathrm{~mm}$ para obtenção da terra fina seca ao ar (TFSA). Estes materiais foram tratados com peróxido de hidrogênio a $30 \%(\mathrm{v} / \mathrm{v})$ em banho-maria a $70{ }^{\circ} \mathrm{C}$ para remoção da matéria orgânica e, posteriormente, com $\mathrm{NaOH} 0,2 \mathrm{~mol} \mathrm{~L}^{-1}$ para a dispersão das partículas. ${ }^{26,27} \mathrm{~A}$ fração areia foi retida em peneira com malha de $0,053 \mathrm{~mm}$ e as frações silte e argila foram recolhidas em provetas de $1000 \mathrm{~mL}$ e separadas por sedimentação, com base na Lei de Stokes. ${ }^{28}$ A secagem desta fração foi feita em liofilizador para preservar a estrutura dos minerais. ${ }^{29}$

A fração argila do argilito foi submetida a três extrações sequenciais com ditionito-citrato-bicarbonato (DCB), ${ }^{30}$ seguidas de uma extração com $\mathrm{NaOH}$ 1,5 mol L-1 31 para solubilizar os óxidos de ferro e caulinita, respectivamente, e concentrar esmectita.

A argila do LVDf foi tratada com $\mathrm{NaOH} 5 \mathrm{~mol} \mathrm{~L}^{-1}$ a quente com a finalidade de extrair caulinita e gibbsita e concentrar óxidos de Fe. ${ }^{32}$ Foi adicionado silício na forma de metassilicato de sódio $\left(\mathrm{Na}_{2} \mathrm{SiO}_{3} .5 \mathrm{H}_{2} \mathrm{O}\right)$ de modo que a concentração na solução fosse 0,2 mol L-1, evitando assim a dissolução de óxidos de Fe com alta substituição isomórfica em $\mathrm{Al} \cdot{ }^{33} \mathrm{~A}$ sodalita $\left[\mathrm{Na}_{4} \mathrm{Al}_{3} \mathrm{Si}_{3} \mathrm{O}_{12}(\mathrm{OH})\right]$ formada foi removida por duas lavagens com $\mathrm{HCl} 0,5 \mathrm{~mol} \mathrm{~L}^{-1},{ }^{32}$ com tempo de contato de 10 min para cada lavagem. ${ }^{34}$

As amostras concentradas dos minerais de argila supracitados foram homogeneizadas e ajustadas em $\mathrm{pH}$ 3,5 (óxidos de $\mathrm{Fe}$ ) e 7,0 (óxidos de $\mathrm{Fe}$ e esmectita) com soluções diluídas de $\mathrm{HCl}$ e $\mathrm{NaOH}$.

A análise mineralógica das frações naturais e concentradas em óxidos de Fe e de esmectita foi realizada através de Difratometria de Raios X (DRX) (Figura 2). Foram montadas lâminas de vidro com amostras em pó (óxidos de $\mathrm{Fe}$ - varredura de 2 a $50^{\circ} 2 \theta$ ) e orientadas (esmectita - varredura de 2 a $22^{\circ} 2 \theta$ ). Os difratogramas foram obtidos com goniômetro vertical Philips, modelo PW 1050/70, equipado com tubo de $\mathrm{Cu}$ e filtro de $\mathrm{Ni}$, operado com $20 \mathrm{~mA}$ e $40 \mathrm{kV}$, com velocidade angular de $0,5^{\circ} 2 \theta \mathrm{min}^{-1}$.

\section{Experimento de sorção}

O experimento de sorção foi conduzido em laboratório, utilizando-se o herbicida Diuron (Figura 1) grau técnico, com $98 \%$ de pureza e procedente da Sigma Aldrich ${ }^{\circledR}$, nas seguintes concentrações: $0 ; 0,25$; 0,$50 ; 0,75 ; 1,00 ; 2,00 ; 3,00 ; 4,00 ; 6,00 ; 8,00 ; 10,00 \mathrm{mg} \mathrm{L}^{-1}$. A sorção de Diuron nas amostras de esmectita concentrada foi realizada em $\mathrm{pH}$ 7,0 e nos óxidos de Fe concentrados em pH 3,5 e 7,0.

Para a preparação das soluções-estoque de Diuron foram pesados $10 \mathrm{mg}$ do herbicida, os quais foram dissolvidos em $4 \mathrm{~mL}$ de álcool etílico. Estas soluções foram transferidas para balões de vidro com capacidade para $1000 \mathrm{~mL}$ e o volume dos frascos foi completado com água ultrapura. $\mathrm{O}$ pH da solução foi ajustado para 3,5 e 7,0 com
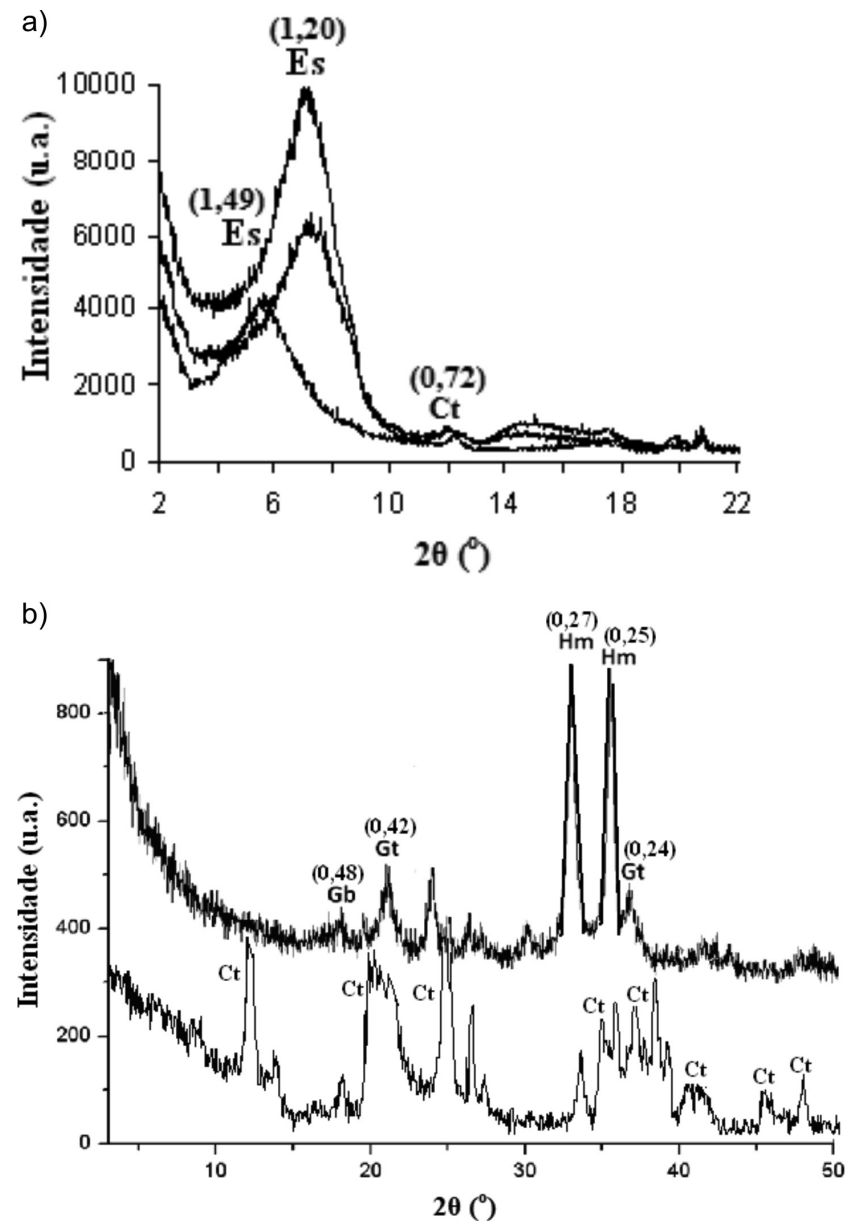

Figura 2. Difratogramas de raios X (radiação $C u K \alpha$ ). a) Amostras orientadas da fração argila do Argilito da Fração Guabirotuba. Os gráficos de baixo para cima correspondem às seguintes frações: argila natural; após tratamento com ditionito-citrato-bicarbonato (DCB); após tratamentos com DCB e com $\mathrm{NaOH}$ $1,5 \mathrm{~mol} \mathrm{~L}^{-1}$. b) Amostras em pó da fração argila do horizonte $B$ do Latossolo Vermelho distroférrico húmico. De baixo para cima: argila natural; após tratamento com NaOH 5 mol L - $^{-1}$ Es - esmectita, Ct - caulinita, Gb-gibbsita, Gt - goethita, Hm - hematita. Os números entre parênteses representam as distâncias (nm) de conjuntos de planos paralelos nos minerais

auxílio de soluções diluídas de $\mathrm{HCl}$ e $\mathrm{NaOH}$. A partir das soluções-estoque foram realizadas diluições seriadas para a obtenção das demais concentrações, ajustando-se sempre o pH para 3,5 e 7,0 e a concentração de álcool etílico para $4 \mathrm{~mL} \mathrm{~L}^{-1}$.

Foram preparadas suspensões em tubos de centrífuga, contendo $90 \mathrm{mg}$ de cada mineral (massa obtida em balança analítica após secagem da amostra a $40{ }^{\circ} \mathrm{C}$ por $24 \mathrm{~h}$ ), $8,00 \mathrm{~mL}$ de solução de Diuron (nas diferentes concentrações e valores de $\mathrm{pH}$ ) e 1,00 mL de $\mathrm{CaCl}_{2} 0,15 \mathrm{~mol} \mathrm{~L}^{-1}$. Provas em branco (sem adição de Diuron) foram preparadas em paralelo para cada um dos argilominerais, adicionando-se $8,00 \mathrm{~mL}$ de água ultrapura. A solução de $\mathrm{CaCl}_{2}$ foi utilizada para auxiliar na decantação da argila, a fim de se retirar posteriormente apenas o sobrenadante. Todos os tratamentos foram realizados em triplicata.

As suspensões foram agitadas em agitador orbital a 120 osc $\min ^{-1}$ por $24 \mathrm{~h}$ - tempo ideal para alcançar o equilíbrio da solução ${ }^{12}$ - e temperatura ambiente, com média de $22^{\circ} \mathrm{C}$. Depois de agitadas, as soluções foram ultracentrifugadas por $30 \mathrm{~min}$ a $20.000 \mathrm{rpm}$ em ultracentrífuga da marca Sigma, mantendo-se a temperatura do aparelho em $22{ }^{\circ} \mathrm{C}$. Em seguida, as fases sobrenadantes obtidas foram filtradas em membrana de $0,45 \mu \mathrm{m}$. O filtrado foi analisado em 
espectrofotômetro da marca Femto, 700 Plus, sendo a leitura realizada na região do ultravioleta (UV), no comprimento de onda de $248 \mathrm{~nm}$, onde se observa maior absorbância do herbicida Diuron. ${ }^{19}$

Partes das mesmas soluções usadas nos ensaios de sorção foram tomadas para calibração e obtenção das curvas analíticas do espectrofotômetro (leitura $248 \mathrm{~nm}$ ): 11 concentrações de Diuron (0 a 10 $\left.\mathrm{mg} \mathrm{L}^{-1}\right)$, 2 valores de $\mathrm{pH}$, álcool etílico $4 \mathrm{~mL} \mathrm{~L}^{-1}$ e $\mathrm{CaCl}_{2} 0,15 \mathrm{~mol} \mathrm{~L}^{-1}$.

A partir da curva analítica obtida (padrões do herbicida), os valores obtidos no espectrofotômetro em absorbância foram convertidos para concentração em equilíbrio $\left(\mathrm{Ce}-\mathrm{mg} \mathrm{L}^{-1}\right)$. A análise dos dados foi realizada através da isoterma de Freundlich. A Equação de Freundlich é dada pela expressão: ${ }^{35,36}$

$$
\mathrm{Q}=\mathrm{K}_{\mathrm{f}} \cdot \mathrm{Ce} \mathrm{e}^{1 / \mathrm{n}}
$$

em que: $\mathrm{Q}=$ razão entre a massa em $\mathrm{mg}$ do soluto adsorvido (Diuron) pela massa em $\mathrm{kg}$ do mineral adsorvente; $\mathrm{Kf}=$ constante de Freundlich que equivale à capacidade de sorção; $\mathrm{Ce}=$ concentração em equilíbrio, após 24 h de contato do mineral com o herbicida (mg L $\left.{ }^{-1}\right) ; 1 / n$ $=$ expoente de Freundlich.

A utilização de diferentes unidades para expressar os valores de Ce e Kf dificulta a comparação entre os estudos de sorção. ${ }^{37}$ Para se obter a forma linear da isoterma de Freundlich, foram tomados os valores $\log$ aritmos de cada parâmetro por meio da equação: $\log \mathrm{Q}=$ $\log \mathrm{Kf}+1 / \mathrm{n} \log \mathrm{Ce}$.

Dessa forma, ao plotar $\log \mathrm{Q}$ versus $\log \mathrm{Ce}$, é obtido o $\log \mathrm{Kf}$ como a interseção da linha e $1 / \mathrm{n}$ como a inclinação da reta, ${ }^{35,36,38}$ parâmetros amplamente utilizados para comparar os mecanismos de sorção. ${ }^{36}$ É importante ressaltar que para o cálculo de Kf, todos os valores de Ce da curva são utilizados, sendo que esse valor é dependente da temperatura (usualmente mantida a $25^{\circ} \mathrm{C}$ ). No presente estudo a faixa de temperaturas se situou entre 18 e $25^{\circ} \mathrm{C}$.

\section{RESULTADOS E DISCUSSÃO}

\section{Caracterização das amostras de minerais da fração argila}

Nos difratogramas de raios $\mathrm{X}$ fica evidente o predomínio de esmectita e óxidos de $\mathrm{Fe}$ (hematita - Hm e goethita - Gt) nas frações argila concentradas (Figura 2).

A pequena ocorrência de caulinita na amostra do Argilito (Figura 2a) é devida à resistência de algumas partículas do mineral à extração com $\mathrm{NaOH}$ 1,5 mol L $\mathrm{L}^{-1}$. Mesmo com essa limitação, optou-se pelo emprego de solução menos concentrada em relação ao método padrão $\left(\mathrm{NaOH} 5 \mathrm{~mol} \mathrm{~L}^{-1}\right.$ a quente, que promove a remoção total da caulinita e da gibbsita). ${ }^{32}$ Melo et al. ${ }^{31}$ trabalharam com dois perfis de Cambissolos Háplicos formados de Argilito da Formação Guabirotuba e observaram que a solução de $\mathrm{NaOH} 1,5 \mathrm{~mol} \mathrm{~L}^{-1}$ foi mais eficiente na concentração de esmectita na fração argila do horizonte mais profundo (C4 - 4,2 a 4,5 m). A solução mais concentrada de $\mathrm{NaOH} 5$ mol L-1 a quente também removeu parte da esmectita, principalmente as partículas da fração argila fina.

Melo et al.${ }^{31}$ identificaram, por testes específicos (saturação com
Li), a estrutura básica do mineral 2:1 como montmorilonita e beidelita, ambas esmectitas dioctaedrais.

Na fração argila de Latossolo Vermelho distroférrico húmico (Figura 2b) as reflexões de óxidos de Fe são majoritárias, com pequena ocorrência de gibbsita, que não interfere no predomínio de CTA da amostra nos valores de $\mathrm{pH}$ do experimento de sorção (PCZ da gibbsita superior a 7,0). ${ }^{39}$

$\mathrm{Na}$ amostra concentrada de óxidos de Fe foram determinadas as características cristalográficas da hematita $(\mathrm{Hm})$ e da goethita $(\mathrm{Gt})$ a partir do difratograma de raios $\mathrm{X}$ (Tabela 1) seguindo os procedimentos descritos por Melo et al. ${ }^{40} \mathrm{~A}$ relação $\mathrm{Gt} /(\mathrm{Gt}+\mathrm{Hm})$ igual a 0,11 indica o predomínio de hematita na amostra. Os principais fatores que favorecem a Hm em detrimento à Gt no solo e, portanto, contribuem para diminuir a relação $\mathrm{Gt} /(\mathrm{Gt}+\mathrm{Hm})$ são os maiores teores de Fe no material de origem, as altas temperaturas, o menor grau de umidade, o maior teor de matéria orgânica e valores de $\mathrm{pH}$ mais altos. ${ }^{33,41,42}$ O maior diâmetro médio do cristal (DMC) da Gt na direção (111) que na direção (110) pode indicar formato acicular do material. ${ }^{43}$ Já para Hm, a proximidade dos valores de DMC sugere o formato isodimensional do mineral. ${ }^{44} \mathrm{~A}$ exposição de grupos funcionais com predominância de CTA em amostras concentradas desses minerais é dependente do tamanho e do formato das partículas (características que definem a ASE).

\section{Sorção de Diuron}

De acordo com os tratamentos - esmectita em pH 7,0 e óxidos de Fe em pH 3,5 e 7,0 - foi possível observar a sorção do herbicida em três condições distintas: com alto predomínio de cargas negativas (esmectita), com alto predomínio de cargas positivas (óxidos de Ferro em pH 3,5) e próximo ao ponto de carga zero (óxidos de Fe em $\mathrm{pH} 7,0$ ).

$\mathrm{O}$ percentual médio de remoção em relação à concentração adicionada (\%) de Diuron seguiu a ordem (Tabela 2): óxidos de $\mathrm{Fe} \mathrm{pH}$ 7,0 > esmectita $\mathrm{pH}$ 7,0 > óxidos de $\mathrm{Fe} \mathrm{pH}$ 3,5. A redução da porcentagem de sorção de Diuron com o aumento da concentração da solução foi mais consistente na matriz com maior sorção (óxidos de $\mathrm{Fe} \mathrm{pH}$ 7,0). Este fato deve-se à diminuição dos sítios de sorção disponíveis. Liu et al., ${ }^{17}$ ao estudarem a cinética da sorção de Diuron em solos (terra fina) em função do tempo de contato, observaram rápida sorção de herbicidas apenas nos estágios iniciais, em função da grande quantidade de sítios disponíveis.

A remoção máxima de Diuron pela esmectita foi apenas 18,8\% (Tabela 2), valor bem próximo ao verificado por Rezende et al. ${ }^{19}$ que encontraram remoção de até $20 \%$ em montmorilonita intercalada com K, na concentração do herbicida de $2,5 \mathrm{mg} \mathrm{L}^{-1}$. Isso demonstra a baixa interação do herbicida não ionizável e de baixa polaridade com uma matriz de elevada CTC e ASE. Rezende et al..$^{19}$ observaram que para a ametrina, herbicida iônico base fraca com predomínio de cargas positivas para valores de $\mathrm{pH}$ inferiores a 4,1 , a remoção foi acima de $92 \%$. O maior potencial adsortivo de pesticidas iônicos (cargas positivas) a matrizes coloidais dos solos (altos valores de CTC) previne a lixiviação e a contaminação do lençol freático com essas substâncias.

Tabela 1. Propriedades cristalográficas dos óxidos de ferro na amostra da fração argila concentrada do horizonte B do Latossolo Vermelho distroférrico húmico*

\begin{tabular}{|c|c|c|c|c|c|c|c|c|}
\hline \multicolumn{4}{|c|}{$\mathrm{d}$ corrigido } & \multirow[t]{2}{*}{$\mathrm{Gt} /(\mathrm{Gt}+\mathrm{Hm})$} & \multicolumn{4}{|c|}{$\mathrm{DMC}$} \\
\hline Gt (110) & Gt (111) & $\operatorname{Hm}(110)$ & $\operatorname{Hm}(104)$ & & Gt (110) & Gt (111) & Hm (110) & Hm (104) \\
\hline ------------ & - & ------- & -------------- & & 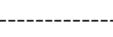 & - & & \\
\hline 0,416 & 0,243 & 0,250 & 0,269 & 0,11 & 17,1 & 32,4 & 24,5 & 23,3 \\
\hline
\end{tabular}

* Distância interplanar corrigida utilizando $\mathrm{NaCl}$ como padrão interno. Relação Gt/(Gt+Hm) e DMC (diâmetro médio do cristal) calculados com base nos difratogramas de raios X. 
Tabela 2. Remoção de Diuron da solução pela sorção aos óxidos de $\mathrm{Fe}$ e esmectita após 24 h de contato do herbicida com os minerais*

\begin{tabular}{cccc}
\hline & \multicolumn{3}{c}{ Remoção de Diuron (\%) } \\
\cline { 2 - 4 } Concentração & \multicolumn{2}{c}{ Óxidos de ferro } & Esmectita \\
\cline { 2 - 4 } Diuron (mg L & pH 7,0 & pH 7,0 \\
\cline { 2 - 4 } 0,25 & 17,7 & 97,7 & 9,7 \\
0,50 & 3,5 & 47,0 & 16,7 \\
0,75 & 2,9 & 26,9 & 8,6 \\
1,00 & 2,6 & 32,7 & 18,8 \\
2,00 & 9,1 & 16,9 & 1,5 \\
3,00 & 8,1 & 20,6 & 13,1 \\
4,00 & 5,8 & 14,9 & 7,5 \\
6,00 & 4,1 & 13,9 & 7,0 \\
8,00 & 6,0 & 12,1 & 9,9 \\
10,00 & 3,8 & 13,1 & 7,7 \\
\hline
\end{tabular}

* Os resultados apresentam desvios padrão inferiores a $10 \%$.

Os dados obtidos da massa de Diuron (mg) por massa de fase mineral $(\mathrm{kg})$ foram plotados em função da concentração remanescente após o tempo de contato de $24 \mathrm{~h}$, sugerindo um perfil linear (curvas não mostradas) o que, de acordo com a classificação de Giles et al. ${ }^{45}$ indica uma partição constante (isoterma do tipo C) entre a superfície do mineral e a solução. ${ }^{22,46}$ Esses dados foram tratados de acordo com o modelo linear de Freundlich ${ }^{35,36,38}$ (log Q versus $\log \mathrm{Ce}$ ), o que gerou as curvas mostradas na Figura 3. As isotermas obtidas sugerem que o processo de sorção foi maior na amostra de óxido de $\mathrm{Fe}(\mathrm{pH} 7,0)$ e menor no óxido de $\mathrm{Fe} \mathrm{pH} 3,5$, corroborando os resultados apresentados na Tabela 2. Esta interação pode ocorrer principalmente por forças intermoleculares, como de van der Waals, e ligações de H. Estes tipos de interações são as mais relevantes para pesticidas de baixa solubilidade e polaridade e não ionizáveis, como o Diuron. ${ }^{47} \mathrm{O}$ modelo de isoterma de Freundlich é considerado apropriado para estudo de sorção em superfícies heterogêneas ${ }^{48}$ e tem sido amplamente utilizado, por ter uma boa linearidade em experimentos com solos. ${ }^{49}$ Pelos parâmetros dessa equação pode-se inferir que os óxidos de Fe em pH 7,0 demonstraram maior capacidade de sorção de Diuron $\left(\mathrm{K}_{\mathrm{f}}\right)$, enquanto que em pH 3,5 houve maior intensidade de sorção (1/n) (Tabela 3). A capacidade de sorção seguiu a ordem:

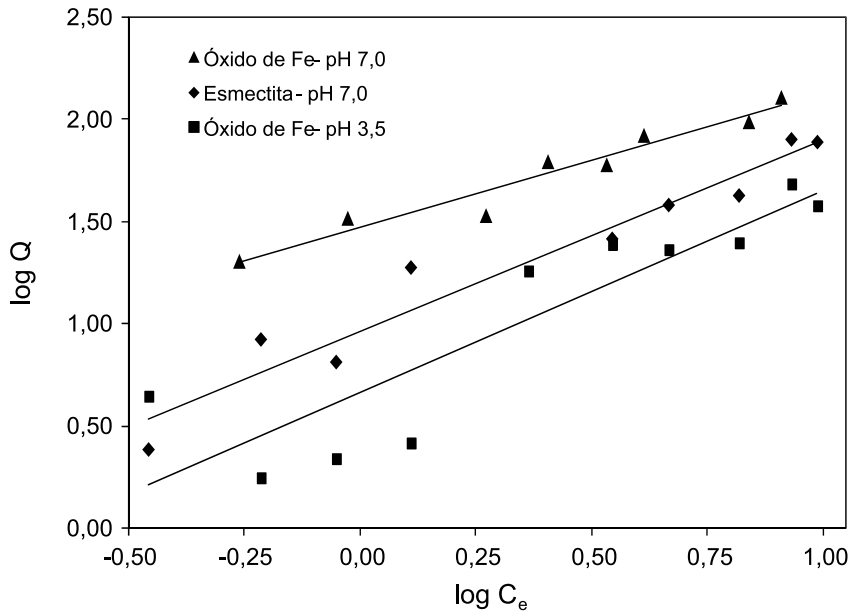

Figura 3. Isotermas de Freundlich representando a sorção de Diuron em amostras da fração argila concentradas em óxidos de Ferro $\mathrm{pH}(3,5$ e 7,0) e em esmectita ( $\mathrm{pH} 7,0)$. Os resultados expressam a média de três experimentos, conduzidos em temperatura ambiente (média de $22{ }^{\circ} \mathrm{C}$ ) óxidos de Fe pH 7,0 > esmectita $\mathrm{pH}$ 7,0 > óxidos de Fe $\mathrm{pH} 3,5$. De acordo com os valores obtidos de $\mathrm{R}^{2}$, entre 0,91 e 0,95 , pode-se inferir que os sistemas estudados foram adequadamente ajustados ao modelo de Freundlich, conforme a Tabela 3.

Tabela 3. Constantes das isotermas de Freundlich para sorção de Diuron em amostras da fração argila concentradas com óxidos de $\mathrm{Fe}(\mathrm{pH} 3,5$ e 7,0) e esmectita $(\mathrm{pH} 7,0)$

\begin{tabular}{lccc}
\hline & \multicolumn{2}{c}{ Óxidos de $\mathrm{Fe}$} & Esmectita \\
\cline { 2 - 4 } & $\mathrm{pH} \mathrm{3,5}$ & $\mathrm{pH} \mathrm{7,0}$ & $\mathrm{pH} \mathrm{7,0}$ \\
\hline $\log \mathrm{K}_{\mathrm{f}}\left(\mathrm{mg}^{1-1 / \mathrm{n}} \mathrm{kg}^{-1} \mathrm{~L}^{1 / \mathrm{n}}\right)$ & 0,50 & 1,47 & 0,94 \\
$1 / \mathrm{n}$ & 1,24 & 0,65 & 0,94 \\
$\mathrm{R}^{2}$ & 0,91 & 0,95 & 0,94 \\
\hline
\end{tabular}

Kf - constante que expressa a máxima capacidade de adsorção de Diuron nas amostras de minerais concentrados; $1 / \mathrm{n}$ - declividade da reta da equação linearizada de Freundlich.

De maneira geral, os valores de $\mathrm{K}_{\mathrm{f}}$ foram baixos e permaneceram na mesma ordem de grandeza de outros estudos de adsorção de Diuron em amostras de solos ${ }^{17} \mathrm{e}$ em minerais de argila. ${ }^{12} \mathrm{~A}$ baixa adsorção de Diuron observada no presente estudo sugere que este herbicida tem grande possibilidade de sofrer lixiviação. De acordo com Pires et al. ${ }^{50}$ quando o produto permanece por mais tempo no solo sem ser adsorvido pelos coloides, degradado e/ou mineralizado, a possibilidade de lixiviar é maior.

Monqueiro et al. ${ }^{51}$ simularam a precipitação pluvial em Latossolo Vermelho distrófico cultivado com cana-de-açúcar e observaram que a combinação de diuron + hexazinone apresentou tendência a ser lixiviada. Eles enfatizaram que este fato pode determinar a seletividade e/ou eficiência no controle de plantas daninhas, bem como o potencial de contaminação de águas subterrâneas. Contudo, esta alta capacidade de lixiviação de Diuron pode ser retardada em solos com maiores teores de matéria orgânica, como observado por Matallo et al. . ${ }^{52}$ Outros experimentos ${ }^{8,53,54}$ também reforçaram a importância da matéria orgânica na adsorção de Diuron, devido à possibilidade do herbicida também ser particionado hidrofobicamente nesse constituinte coloidal. Como se trata de um herbicida com baixa solubilidade em água, o Diuron pode ser atraído fisicamente aos sítios hidrofóbicos da matéria orgânica, otimizando o processo de adsorção. ${ }^{45,46}$ Já os minerais da fração argila, mesmo apresentando alta ASE, como a esmectita, não possuem sítios hidrofóbicos para abrigar o herbicida e, portanto, predominam outros tipos de interações intermoleculares, como de van der Waals e ligações de hidrogênio. ${ }^{47}$

Rocha et al..$^{55}$ avaliaram a capacidade adsortiva de imazaquim (herbicida ácido fraco com predomínio de cargas negativas para valores de $\mathrm{pH}$ superiores a 3,8) em Latossolo oxídico com características semelhantes ao solo utilizado no presente estudo: material de origem basalto; solo muito argiloso; amostra coletada em subsuperfície (horizonte $\mathrm{Bw}$ ) com baixo teor de matéria orgânica. O maior valor de $\mathrm{K}_{\mathrm{f}}$ para adsorção de imazaquim em pH 5,1 $(2,17)$ em relação ao $\mathrm{pH}$ neutro $\left(\mathrm{K}_{\mathrm{f}}=0,31\right)$ foi atribuído à maior ocorrência de cargas positivas (CTA) nos óxidos de $\mathrm{Fe}$ e $\mathrm{Al}$ em $\mathrm{pH}$ ácido. Como os autores trabalharam com amostras de solo, constituído de diferentes minerais na fração argila, a elevação de $\mathrm{pH}$ para 6,9 resultou em aumento de cargas negativas na caulinita (PCZ próximo a 3,5) e redução de CTA nos óxidos de Fe e $\mathrm{Al}$ (PCZ entre 7 e 9), o que determinou menor atração eletrostática desses minerais com o imazaquin. Já no presente trabalho, mesmo se tratando de herbicida não iônico, a utilização apenas de minerais da fração argila resultou em maior capacidade de adsorção de Diuron em pH neutro $\left(\mathrm{K}_{\mathrm{f}}=1,47\right.$ - Tabela 3$)$.

Nos estudos com amostras de solos, por ser uma matriz composta, 
o estabelecimento de relação causa-efeito para determinar a influência de cada contribuinte coloidal na adsorção de herbicidas é feito de forma indireta, por análises de correlações. ${ }^{9}$ A maior capacidade adsortiva do Diuron na amostra de óxidos de Fe pH 7,0 (Tabela 3) pode ser atribuída à menor condição de repulsão entre o herbicida não iônico e a superfície dos minerais. Devido à proximidade do $\mathrm{PCZ}$ desses minerais (próximo a $\mathrm{pH} 8,0)^{23}$ no $\mathrm{pH} 7,0$, espera-se maior equilíbrio entre cargas positivas e negativas, o que facilitou a interação mútua das partículas de hematita e goethita (predomínio de hematita, Tabela 1). Essa aparente condição de neutralidade, provavelmente, favoreceu a aproximação e a partição do Diuron na fase sólida. Neste caso, também há favorecimento, além das ligações de $\mathrm{H}$, de interações dipolo-dipolo (van der Waals), pois essas associações são mais significativas para moléculas em contato mais próximo com a superfície adsorvente. ${ }^{47}$

A capacidade de adsorção maior em pH 7,0 em relação a pH 3,5 difere de resultados obtidos por outros pesquisadores, ${ }^{17,56,57}$ que observaram maior adsorção de Diuron quanto maior a acidez. Porém, as condições de adsorção foram diferentes: Bailey et al ${ }^{56}$ estudaram apenas esmectita, a qual apresentou condições intermediárias no presente estudo quando comparada aos óxidos de Fe; Chaplain et al ${ }^{57} \mathrm{e}$ Liu et al. ${ }^{17}$ estudaram solos (terra fina seca ao ar) com a presença de matéria orgânica, o que pode dificultar bastante a comparação, visto que os coloides orgânicos, além de apresentarem outros mecanismos de adsorção, podem cobrir as superfícies minerais alterando, portanto, o processo de sorção.

A menor adsorção de óxidos de $\mathrm{Fe}$ em $\mathrm{pH}$ 3,5 pode ser atribuída ao excesso de cargas positivas e, portanto, de CTA dos minerais, que reduz a interação do adsorbato com o herbicida não iônico e a possibilidade de ligações intermoleculares. Mesmo com a elevada CTC da esmectita - o que também dificulta a proximidade com os herbicidas - sua elevada área superficial específica (ASE - aproximadamente $\left.700 \mathrm{~m}^{2} \mathrm{~g}^{-1}\right),{ }^{21}$ provavelmente, aumentou a adsorção do Diuron em relação aos óxidos de $\mathrm{Fe}$ pH 3,5, colocando o mineral em posição intermediária na sequência de adsorção (Figura 3, Tabela 3).

\section{CONCLUSÕES}

A caracterização dos minerais por difratometria de raios $\mathrm{X}$ demonstrou predomínio da hematita na fração argila de LVdf tratada com NaOH $5 \mathrm{~mol} \mathrm{~L}^{-1}$ e de esmectita na fração argila de argilito tratada com ditionito-citrato-bicarbonato e $\mathrm{NaOH} \mathrm{1,5} \mathrm{mol} \mathrm{L}^{-1}$.

As frações minerais demonstraram baixa capacidade de adsorção do herbicida Diuron, em pH 3,5 e 7,0, o que favorece sua lixiviação e contaminação do nível freático em solos com baixos teores de matéria orgânica (grande maioria dos solos tropicais).

A maior capacidade de sorção foi observada para óxidos de Fe em pH 7,0, seguida de esmectita em pH 7,0 e óxidos de Fe em pH 3,5. A proximidade do $\mathrm{pH}$ do ponto de carga zero da hematita e goethita na primeira situação, provavelmente, favoreceu a sorção do herbicida não iônico e de baixa polaridade.

\section{REFERÊNCIAS}

1. Traghetta, D. G.; Sposito, G.; Vieira, E. M.; Machado, S. A. S.; Mazo, L. H.; Avaca, L. A.; Vaz, C. M. P.; Crestana, S.; Martin-Neto, L.; Comunicado Técnico EMBRAPA 1996, 14, 1.

2. Armas, E. D.; Monteiro, R. T. R.; Amâncio, A. V.; Correa, R. M. L.; Guercio, M. A.; Quim. Nova 2005, 28, 975.

3. Mangrich, A. S.; Giannonia, R. A.; Lombardi, K. C.; Pereira, B. F.; Olendzki, R. N.; Guimarães, E.; Budziak, C. K.; Novotny, E. H.; Anjos, A.; Silva, F. A.; Santos, J. C. P.; Valle, T.; Vugmanb, N. V.; Met. Mat. Processes 2005, 17, 243.
4. Porto, M. F.; Milanez, B.; Ciênc. saúde colet. 2009, 14, 1983.

5. Abhilash, P. C.; Singh, N.; J. Hazard. Mater. 2009, 165, 1.

6. http://faostat.fao.org/site/424/DesktopDefault.aspx?PageID=424\#ancor, acessada em Dezembro 2010.

7. Vieira, E. M.; Prado, A. G. S.; Landgraf, M. D.; Rezende, M. O.; Quim. Nova 1999, 22, 305.

8. Boeira, R. C.; Souza, M. D.; Circular Técnica EMBRAPA 2004, 9, 1.

9. Vivian, R.; Guimarães, A. A.; Queiroz, M. E. L. R.; Silva, A. A.; Reis, M. R.; Santos, J. B.; Planta Daninha 2007, 25, 97.

10. Prata, F.; Lavorenti, A.; Regitano, J. B.; Tornisielo, V. L.; Rev. Bras. Ciênc. Solo 2000, 24, 217.

11. Rodrigues, B. N.; Almeida, F. S.; Guia de Herbicidas, $5^{\text {a }}$ ed., Instituto Plantarum: Londrina, 2005.

12. Bouras, O.; Bollinger, J.; Baudu, M.; Khalaf, H.; Appl. Clay Sci. 2007, 37, 240.

13. Giacomazzi, S.; Cochet, N.; Chemosphere 2004, 56, 1021.

14. http://www.seab.pr.gov.br/arquivos/File/defis/DFI/Bulas/Herbicidas/ DIURON NORTOX.pdf, acessada em Maio 2012.

15. WSSA - Weed Science Society of America; Herbicide Handbook, Weed Science Society of America: Champaign, 1989.

16. Field, J. A.; Reed, R. L.; Sawyer, T. E.; Griffith, S. M.; Wigington, P. J.; J. Environ. Qual. 2003, 32, 171.

17. Liu, Y.; Xu, Z.; Wu, X.; Gui, W.; Zhu, G.; J. Hazard. Mater. 2010, 178, 462.

18. Dousset, S.; Thevenot, M.; Schrack, D.; Gouy, V.; Carluer, N.; Environ. Pollut. 2010, 158, 2446.

19. Rezende, E. I. P.; Peralta-Zamora, P. G.; Abate, G.; Quim. Nova 2011, $34,21$.

20. Borchardt, G. Em Minerals in soil environment; Dixon, J. B.; Weed, S. B., eds.; Soil Science Society of America: Madison, 1989, cap. 14.

21. Schulze, D. G. Em ref. 20, cap. 1.

22. McBride, M. B.; Environmental Chemistry of Soil, Oxford University Press: New York, 1994.

23. Costa, A. C. S.; Bigham, J. M. Em Química e Mineralogia do Solo - Parte I; Melo, V. F.; Alleoni, L. R. F., eds.; Sociedade Brasileira de Ciência do Solo: Viçosa, 2009, cap. 8.

24. Ghidin, A. A.; Melo, V. F.; Lima, V. C.; Lima, J. M. J. C.; Rev. Bras. Ciênc. Solo 2006, 30, 293.

25. Salamuni, E.; Stellfeld, M. C.; B. Paranaense Geoci. 2001, 49, 21.

26. Jackson, M. L.; Soil chemical analysis - advanced course, Prentice-Hall: Madison, 1979.

27. Kunze, G. W.; Dixon, J. B. Em Methods of soil analysis - Part I; Klute, A., ed.; American Society of Agronomy: Madison, 1986, cap. 5.

28. Gee, G. W.; Bauder, J. W. Em ref. 27, cap. 15.

29. Melo, V. F.; Wypych, F. Em ref. 23, cap. 7.

30. Mehra, O. P.; Jackson, M. L.; Clay Clay Miner. 1960, 7, 317.

31. Melo, V. F.; Mattos, J. M. S. M.; Lima, V. C.; Rev. Bras. Ciênc. Solo 2009, 33, 527.

32. Norrish, K.; Taylor, M.; J. Soil Sci. 1961, 12, 294.

33. Kämpf, N.; Schwertmann, U.; Clays Clay Miner. 1982, 30, 401

34. Singh, B.; Gilkes, R. J.; Clay Miner. 1991, 26, 463.

35. Site, A. D.; J. Phis. Chem. Ref. Data 2001, 30, 187.

36. Sparks, D. L.; Environmental soil chemistry, Academic Press: San Diego, 1995.

37. Chen, Z.; Xing, B.; McGill, W. B.; J. Environ. Qual. 1999, 28, 1422.

38. Coles, C. A.; Yong, R. N.; Engineering Geology 2006, 85, 19.

39. Alleoni, L. R. F.; Mello, J. W. V.; Rocha, W. S. D. Em Química e Mineralogia do Solo - Parte II; Melo, V. F.; Alleoni, L. R. F., eds.; Sociedade Brasileira de Ciência do Solo: Viçosa, 2009, cap. 12.

40. Melo, V. F.; Fontes, M. P. F.; Novais, R. F.; Singh, B. ; Schaefer, C. E. G. R.; Rev. Bras. Ciênc. Solo 2001, 25, 19.

41. Schwertmann, U.; Kämpf, N.; Soil Sci. 1985, 139, 344.

42. Schwertmann, U.; Taylor, R. M. Em ref. 20, cap. 8. 
43. Amarasiriwardena, D. D.; Bowen, L. H.; Weed, S. B.; Soil Sci. Soc. Am J. 1988, 52, 1179.

44. Schwertmann, U.; Fitzpatrick, R. W.; Taylor, R. M.; Lewis, D. G.; Clays Clay Miner. 1979, 27, 105.

45. Giles, C. H.; Smith, D.; Huitson, A.; J. Colloid Interface Sci. 1974, 47, 755.

46. Hinz, C.; Geoderma 2001, 99, 225.

47. Oliveira Jr., R. S.; Regitano, J. B. Em ref. 39, cap. 15.

48. Ho, Y. S.; Porter, J. F.; McKay, G.; Water, Air, Soil Pollut 2002, 141, 1.

49. Francioso, O.; Bak, E.; Rossin, N.; Saqui, P.; The Sci. of the total Environ. 1992, 123/124, 503.

50. Pires, N. M.; Silva, J. F.; Silva, J. B.; Ferreira, L. R.; Cardoso, A. A.; $R$ Ceres 1997, 44, 300.

51. Monqueiro, P. A.; Amaral, L. R.; Binha, D. P.; Silva, A. C.; Silva, P. V.; Planta Daninha 2008, 26, 403.
52. Matallo, M. B.; Luchini, L. C.; Gomes, M. A. F.; Spadotto, C. A.; Cerdeira, A. L.; Marin, G. C.; R. Ecotoxicol. Meio Ambiente 2003, 13, 83.

53. Prata, F.; Lavorenti, A.; Rev. Biociênc. 2000, 6, 17.

54. Albuquerque, M. A.; Schaefer, C. E. G. R.; Foloni, J. M.; Ker, J. C.; Fontes, L. E. F.; R. Bras. Ciênc. Solo 2001, 25, 179.

55. Rocha, W. S. B.; Alleoni, L. R. F.; Regitano, J. B.; Casagrande, J. C.; Tornisiello, V. L.; R. Bras. Ciênc. Solo 2000, 24, 649.

56. Bailey, G. W.; White, J. L.; Rothber, G. T.; Soil Sci. Soc. Am. J. 1968, $32,222$.

57. Chaplain, V.; Brault, A.; Tessier, D.; Défossez, P.; Eur. J. Soil Sci. 2008, 59, 1202. 